\title{
AUDIBLE MINORITIES AND DISCRIMINATION: AN OVERVIEW
}

\author{
Las minorías audibles y discriminación: una visión general
}

Erwin J. Warkentin ${ }^{1}$

Recibido 02/01/2020

Aceptado 15/02/2020

\begin{abstract}
This article deals with research into the importance of native or near native pronunciation of a person's L2 or L3 and the prejudices faced by those who may speak an accented form of a majority language. In order to reach its conclusions, the article analyses research focused on the learning of English as an L2 or L3 undertaken over the last 50 years. It concentrated on the impact of accented speech and the biases for and against accented speakers of a majority language and identifies where these findings converge and diverge. These results also indicate that the concerns of researchers have shifted as the perceptions of foreigners within English-speaking societies have changed over time. Ingroups are identified as important in determining the relative values of accents and that accented speakers constitute an audible minority and exert pressure on its members to maintain the "accentedness" of their speech. In defining the nature of an audible minority, the article indicates that this can be as powerful a factor as that of skin colour in some societies. In the end, it questions whether meticulous uniformity in spoken language is important or even desirable. The article concludes by suggesting that the problem of the audible minority is more that of the listener than the speaker since many of the myths surrounding accentedness and intelligibility have been proven false.
\end{abstract}

Keywords: audible minorities, native pronunciation, language prejudices, minority language, majority language

\section{RESUMEN}

Este artículo presenta una investigación sobre la importancia de la pronunciación nativa o casi nativa del L2 o L3 de una persona y los prejuicios que enfrentan aquellos que hablen una forma acentuada de un idioma mayoritario. Para llegar a sus conclusiones, el artículo analiza investigaciones centradas en el aprendizaje del inglés como L2 o L3 realizadas en los últimos 50 años. Se concentró en el impacto del discurso acentuado y los prejuicios a favor y en contra de los hablantes acentuados de un idioma mayoritario e identifica dónde convergen y divergen estos hallazgos. Estos resultados también indican que las preocupaciones de los investigadores han cambiado a medida que la percepción de los extranjeros en las sociedades de habla inglesa ha cambiado con el tiempo. Los grupos dentro de grupos se identifican como importantes para determinar los valores relativos de los acentos y que los hablantes acentuados constituyen una minoría audible y ejercen presión sobre sus miembros para mantener el "acento" de su discurso. Al definir la naturaleza de una minoría audible, el artículo indica que este puede ser un factor tan poderoso como el del color de la piel en algunas sociedades. Al final, cuestiona si la meticulosa uniformidad en el lenguaje hablado es importante o incluso deseable. El artículo concluye sugiriendo que el problema de la minoría audible es más del oyente que del hablante, ya que muchos de los mitos que rodean el acento y la inteligibilidad se han demostrado falsos.

Palabras clave: minorías audibles, pronunciación nativa, prejuicios lingüísticos, idioma minoritario, idioma mayoritario

\section{Introduction}

In research dealing with various issues concerning foreign language acquisition, at least in a North American English language context, considerable effort has been expended in trying to understand accent perception. The underlying question being: Is it imperative to have students concentrate on pronunciation in the oral production of a given language over other aspects of spoken production of a given language, to produce a spoken form of the

${ }^{1}$ Memorial University of Newfoundland 
language that does more than approximate a native speaker's pronunciation? Or, to put it another way: Does an accent inhibit an individual's ability to make themselves understood, and if so, where is the fault line between acceptable and unacceptable pronunciations? As will be outlined more fully below, the problems surrounding accented speech has been looked at from several perspectives. A study of articles written over the last 50-years reveals that there is agreement among most scholars that accented speech can cause difficulties in communicating ideas. However, there is no consensus on why this is the case and how the problem, if there is indeed is a problem with accented speech, ${ }^{2}$ might be rectified.

Accented speech is a difficult concept to deal with since the notion is difficult to encapsulate without several codicils attached to it in order to make it fit a given context. It is quite simply a very subjective term with a definition that can easily change based on who is speaking the "standard" form of a given language. Simply put, a person who is perceived to have no accent in one context may well be considered to have an accent, even a strong one, at another time in a different place where the ingroup speaks a different variant of the same language.

For this article, accented speech is understood as being the speech of an individual that has intonations in their oral language production that marks them as different from the members of an ingroup with whom they are engaging in speech-acts. This is not to denigrate looking at the "nuts and bolts" of accent perception. They are necessary for understanding the dynamics of a conversation that is challenged by the speakers not having matching accents.

Investigations beginning in the 1970s, though research along these lines had already been undertaken to some degree prior to this, finds researcher almost unanimously agreeing that discrimination based on accent did occur — the only disagreement being in the degree to which it does. A somewhat smaller group questioned whether all accents suffered under the same prejudice or whether some accents were valued more than others and whether this led to social stigmatisation. The consensus among investigators is that ingroups do distinguish between accents and value some over others, the same biases occurred whether the accent was an accepted variant or dialect of the ingroup's language or if it was an accent caused by interference from a foreign language. The main point of contention is how the problem is to be remedied. Is the question the speaker's problem and his or hers to the rectify or if accent discrimination is culture-driven and is only an issue if the listener is conditioned to believe that it represents a threat to the ingroup. From this then flows the discussion whether it is possible to formulate an intervention that would treat the situation either by extinguishing the speaker's accent and normalising their oral language production or whether the solution lies within the manipulation of popular culture of a given ingroup thus changing the perception of an accent.

\section{The Problem}

One of the issues that has confronted language teachers is the issue of how to judge a language learner's proficiency in the new language that they are learning. To this end, scales have been developed to assist in determining a shared understanding and vocabulary for how the ability of language learners categorised. One that has achieved some modicum of universal acceptance is the Common European Framework of Reference for Languages (CEFR). It allows government agencies and private companies, among other organisations, to develop expectations of what individuals are capable of understanding and expressing in the

\footnotetext{
${ }^{2}$ The Council of Europe (Language Policy Division) in fact brushes potential problems with accented speech aside suggesting that it is not the problem of the speaker, but rather an issue that arises in monolingual societies with no tradition of many, if not most, individuals being bilingual at least to some degree.
} 
work and social settings. Its focus "is the linguistic integration of migrants (adults and young people, and also refugees)." ${ }^{3}$ While it covers in detail how language coding and decoding is judged to categorise students, its view of pronunciation and accent is dismissive. The Council of Europe's Language Policy Division concludes that in international contexts accents are not a hindrance to being understood and that pronunciation tends "to be over-influenced by their lack of familiarity with the accents of speakers of other mother tongues" who are accustomed to working in a monolingual environment. ${ }^{4}$

This may be satisfactory on a theoretical plane functioning within large corporations, universities, and European Council bureaucracies. However, the application of these ideals does not easily survive everyday situations involving individuals who do not know of the nuances of how L2 or L3 speakers communicate in a foreign language and may have no tolerance of different accents.

When debating how humans express thoughts and feelings to one another through articulated sounds, academics have come to a consensus that, if these articulated sounds do not conform to a very narrow band of accepted sounds used by a particular group, accented speech is likely to lead to the speaker of this "imperfect" form of oral language to be stigmatised and discriminated against. ${ }^{5}$ There does not appear to be a particular linguistic community that does this more or less than others. It seems that they all do it equally, only the type of accent that is discriminated against changes depending on the cultural milieu of the ingroup.

\section{What is an Accent?}

The most studied language regarding accented speech is English. This is not surprising since English is the world's most common second language and due to its status as the world's lingua franca. There are simply more opportunities for one to hear an accented form of English and one would then logically encounter the greatest variety of accents in that language. Due to this special status as a language that is commonly used by groups as a means of communication in which potentially none of the participants in a conversation have English as their mother-tongue, it is essential to determine whether certain assumptions involving accented speech and intelligibility are correct. The fundamental question would revolve around determining at what point individuals might no longer be able to understand one another.

While this is an important question, there is another line of inquiry that has been followed that is vital to understanding how accented speakers are accepted into societies where English is the mother-tongue and what it means to be a member of an audible minority.

What is an accent as opposed to a dialect? An accent is the differences in the way in which a non-native speaker of a language (L2) ${ }^{6}$ will shape the sounds of an additional language not learned in childhood as the pronunciation is affected by the speaker first language (L1). These accents are not random and are predictable. For example, a German L1 speaker who has learned English (L2) will predictably have trouble producing the English

\footnotetext{
${ }^{3}$ Council of Europe. Language Policy Division. "Relating Language Examinations to the Common European Framework of Reference for Languages: Learning, Teaching, Assessment (CEFR). A Manual," (2009) [page 42].

${ }^{4}$ Council of Europe.

${ }^{5}$ Bouchard Ryan (1977\& 1982), CBC (2009), Munro \& Derwing (1995), Lindemann (2005), Szabo (2006), Kinzler (2007), Ng (2007), Derwing \& Munro (2009), Kang (2009), Lev-Ari \& Keysar (2010), Derwing \& Waugh (2012), Fuertes et. al. (2012), Cauldwell (2014), Hogenboom (2018).

${ }^{6}$ This can include other subsequent languages learned later in life which may be referred to as L3, L4 etc.
} 


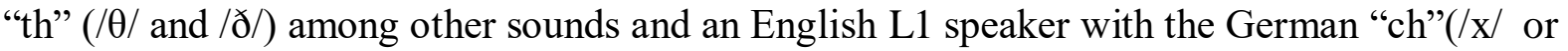
/ç/) phoneme.

An L1 speaker may also have an accent and may at the same time have command of a dialect in a language. This, however, is a little more subtle. An individual might be considered an L1 speaker of both the standard for of their L1 language and of a dialect of that language. However, when speaking the standard variant of their mother-tongue/native language, there may be a discernible accent in the standard language that is as predictable as it would be with a foreign L1 speaker. For example, in parts of Newfoundland, Canada, depending on from where the original settlers of a community came, the initial " $h$ " in words such as "Harbour Grace" is dropped so that it sounds more like "'arbour Grace." "These sounds can sometimes then be replicated when the individual is speaking the standard language. While they may in every other way be speaking the standard language, it is accented by their dialect.

This paper, however, is not about the subtle distinctions between dialect and accent, though some of the same prejudices may spill over from accented L1 to an individual who might be considered to be speaking a perfectly intelligible dialect of a given standard language variant. There will be a few cases where examples of dialect and accent are parallel and will be explored further.

\section{Defining an Audible Minority and Discrimination}

The Language Policy Division of the European Council, whose purpose it is to integrate refugees and immigrants into their new cultural and linguistic contexts, suggests that accent is not a significant concern from a pragmatic perspective. While it is admirable to suggest that the accent of an individual does not matter, as long as they effectively communicate in the new language, this assumes that language is used only for business transactions, whether that is at the local grocery store or working for an international banking concern, and that the recipient makes no judgements of the speaker based on sounds that do not conform to what he or she considers standard pronunciation. Language is much more than something used for transactional purposes. It is what creates the spirit and soul of a people and can, at times, play on human emotions.

Cargile and Giles (1997) recognise the role that emotions play a role in how accents are understood. In this case, I use the term "understood" because emotions do indeed seem to create a context within which a listener decodes what is being said. It also notes that people associate specific attributes to particular accents. A typical example is British Received Pronunciation (RP). If an American listener hears someone speak in this accent, they usually ascribe "culturedness" and sophistication to that individual. The question, of course, is where these ideas come from. Judgement would be based on the consensus and context provided by popular culture. One should not underestimate the power exerted by a character such as James Bond on how the British accent might be understood by someone who speaks with a different native accent. It creates an initial feeling of trust for someone who speaks in RP. It need not be the case that he or she has proven him or herself trustworthy prior to this first meeting.

Research into the impact of accents and how people assimilate into a social group has led to several significant conclusions. Most significantly, they have found that reactions to accents, whether conscious or not, sometimes reveal a side of people that they may wish to

\footnotetext{
7"E drops 'is h in 'Olyrood and picks en up in H'Avondale" is an idiom used in Newfoundland that describes one of the peculiarities of the variants of this Canadian-English dialect. More information on Newfoundland English variation may be found at the database maintained by the Memorial University of Newfoundland athttps://dialectatlas.mun.ca/about/.
} 
conceal. For example, when a speaker of Standard English hears a foreign accented speaker of the standard language, he or she may jump to what in normal circumstances might be considered hasty conclusion about the accented speaker based on "gut-instinct" and feelings. ${ }^{8}$

Over the last fifty years, findings have consistently concluded that prejudice, bias, and discrimination go beyond judgments made based on skin colour. Moreover, the discrimination is not just visually conditioned, but determined by auditory cues as well. Sometimes prejudices and hasty conclusions are based solely on auditory cues given by individuals who speak an "imperfect" form of any given language. It has also been revealed that auditory cues often allow for even finer distinctions in terms of whom one might discriminate against than even skin colour. This is the result of the sounds the listener is hearing being identified with specific ideas and emotions than what might be communicated by visual clues that have been conditioned into the listener by his or her cultural milieu.

The way things are said can be quite revealing about an individual's education and possible ideological and political bent. It provides an insight not only into the person's ancestors and where they may have originated from but allows for tenuous assumptions to be made about the speaker's belief systems, political bent, and what they might think of the listener. All of this is dependent upon the judgment that we make about the education that the speaker may or may not have received and how they were indoctrinated in the early years of their lives. Much like skin colour, an individual with a given accent might have very little control over the verbal cues they drop into conversations with people who may unconsciously be listening for ways of determining whether the individual is part of an ingroup or outgroup.

\section{The Valuation of an Accent}

Research finding published over the last 50 years makes it clear that an accent may be understood in one of two ways. Hearing an accent may lead an individual to make conclusions regarding whether they are superior or inferior to their interlocutor (or that they are of equal status). Kahane (1986) determined that having command of a "prestige language" demonstrates to the world that one has "education" or at the very least, the "appearance or pretence of education." Moreover, that it once was the case that bi- or trilingualism was a sign of being educated and even of being "civilised." This, however, has changed to some degree. Today, one needs English in order to function in a global world. That, however, does not require one to be bi- or trilingual. For some, it means that they can remain monolingual and cultivate what might be perceived as a prestige dialect. However, what was once considered a prestige accent can just as quickly become a symbol of elitism or of being a colonial overlord. It can then have quite the opposite effect. Nonetheless, published research demonstrates that individuals, even if unconsciously, make judgements about others and their beliefs based on the accent they were hearing. It is these socially constructed biases by ingroups that research suggests cause increased social cohesion to be formed, for good or for bad. ${ }^{9}$

In a study conducted for the BBC, Melissa Hogenboom (2018) investigated the relative prestige of accents within the British English-speaking environment. She used RP as the standard of what she described as "the language of the elites, power and royalty." Analysis of data collected revealed that people were quick to make judgements based on the accents they heard. In a split-second, subjects categorised an individual into any number of rubrics based solely on the sounds used to communicate the English language. Hogenboom

\footnotetext{
${ }^{8}$ This can apply to a "non-standard" form of a spoken language as well.

${ }^{9}$ Bouchard Ryan (1982), Dobrow \& Gidney (1998), Gatbonton et al. (2005), Szabo (2006), Kinzler et al. (2007), Kang \& Rubin (2009), Jiang et al. (2018), Reid et al. (2019).
} 
further noted that attitudes were changing in the United Kingdom towards the various accents that might typically be heard in the UK but that RP was still the accent that held the highest prestige, while accents such as Liverpudlian and Cockney were generally mistrusted trusted, according to popular wisdom.

From this, one might extrapolate that the same or a similarly conditioned reflex occurs when a North American English speaker hears accented English. While there may be desirable and trusted accents, there are also those that may be considered undesirable to the North American ear. For example, a North American English speaker, in the split second that he or she might hear an "Indian" accent on the telephone, they would react reflexively by hanging up or simply mistrusting anything said by the individual calling. ${ }^{10}$

Most studies have found that an accent affects the believability of an individual as differentiated from the truthfulness of a given statement that an individual might make. ${ }^{11}$ From these results, it becomes clear that the problem lies with the decoder of the message and not the encoder. If one were to receive the message as an anonymous text or in Morse code, one would have to decide on the merits of what was said, and not how it was said, or it might "sound." This recent approach the problem promises to take some of the onus of being understood from the speaker and place it with the listener as an equal in the communication act.

The question is, what is used as the basis for these rather quickly reached determinations? They are certainly seldom formally taught, though there may be some examples of this being the case. In 1998, Dobrow and Gidney published the results of their study on the impact of popular culture on the development of language in children and ultimately how they perceive and judge accents. These linguistic reflexes appeared, according to their findings, challenging to extinguish later. It suggests that the learned responses to accents continue into adulthood, even if only in an unconscious state. This might explain how we make relatively quick decisions about whether we are going to trust someone or not. It notes that one of the Cold War icons that remained within children's programming was that of the German accent as the accent of evil. ${ }^{12}$

The accented speaker also has a part to play in the manipulation of attitudes during a conversation. It has been found that individuals will sometimes modulate between accents depending on who their conversation partner might be. Szabo (2006) focuses on how people use accents to create identities. That is, she suggests that accents are flexible and may be used to affect reactions from the listener based on manipulating the accent employed. This is not what a linguist might call register and is consciously employed in specific contexts in order to further the goals of the speaker's own goals. Far from revealing hidden things about themselves, Szabo argues that L1 speakers (in this case, of English) who are members of a distinct group which has a foreign language as there L1 within a larger host group, may use accents in order to construct an image of themselves for their listeners. It is in this way that they negotiate their identity within another group. By modulating an accent, an individual can manipulate, to some degree, how an ingroup understands his or her culture as revealed by their accent.

\footnotetext{
${ }^{10}$ Wang et al (2013) examine "customer biases relating to employee accents in call service encounters." They worked from the assumption "that customers automatically evaluate call service employees with a nonstandard accent lower than employees with a standard accent." Their data suggested that this was only the case when a negative service outcome resulted. However, they limited their study to customer-initiated interactions. Even so, there was a greater likelihood that the customer would judge the accented service representative more harshly. ${ }^{11}$ Lev-Ari\& Keysar (2010), Hogenboom (2018), Jiang et al. (2018), McGill University (2018).

${ }^{12}$ It would be helpful to repeat the study now more than twenty years later to determine to what extent it has remained the case, or, if the bias is shifting to other accents as the image of the typical villain changes in the popular culture of the English-speaking world.
} 
It appears that there is something else going on in the minds of listeners when they hear someone speaking with an accent. Research suggests that an accent is not really an impediment to understanding the speaker. The ingroup allows itself to exclude an individual from the greater dialogue due to the otherness of the individual as demonstrated by the fact that they have a "foreign" accent,an accent that belongs to someone who would not have the best interests of the dominant social group at heart. In other words, ingroups allow a primordial part of their collective thought process to determine whether it is going to allow a particular individual into the group and further allow them to become a trusted member of that group.

Speakers will modulate accent according to the group being addressed, can be twoedged. According to Szabo, when one speaks with an accent, one not only aspires to the accepted culture; but, in turn, can be seen as a traitor to the group of origin. ${ }^{13}$ By not maintaining the accepted accent of one's mother tongue, it could show that one has rejected or abandoned one's roots. Thus, speaking with or without an accent becomes a balancing act as these bilingual/bi-cultural individuals try to negotiate the passage between the two selves that have been created as a result of being at home in two languages. They find themselves having to consider the peer pressure from both the ingroup and outgroup, which may be fully interchangeable labels in this instance.

The significance of speaking with an accent was further revealed by Derwing and Munro (2009) and focused on the role of accent as a potential obstacle to communication. They concluded that while accents have been blamed for miscommunications, that this explanation was usually used as a cover-up for racism and discrimination against speakers who may not measure up to the received pronunciation of a particular region or country. They explain that "the generally accepted goal of pronunciation teaching was native-like speech" (Derwing \& Munro 481). Here, however, one can once again see the influence of high and low culture on how language production is perceived.

Derwing and Munro do emphasize the need for pronunciation practice and view deviations from standard pronunciations as being like a medical or psychological problem that can be "cured" with the right treatment. One of the approaches suggested seems to view a person speaking with an accent to having something akin to a medical condition or problem. As such, it could then be dealt with, in a systematic way once one has determined what the cause of the problem was in the first place. That way, the action could be identified and treated, and the individual could then fit into society without any further difficulties.

What they do not consider is that human beings do reach a limit in terms of how much they can improve their pronunciation in a second language. Language production, after all, is a physical skill that is learned or acquired through practice and training. It is much like walking or running. Most humans can walk or run. However, there is considerable variation in how fast or far one may run as determined by the limits of one's body or physical habits that one may have learned previously. We do know that language is best learned young, and that the ability to learn new language skills diminishes with age.

Of greater interest is Derwing and Munro's exploration of the relationship between accent and identity. They go so far as to question the ethics of changing someone's accent, suggesting, that in doing so, one is tampering with the personality of an individual. They do point out the research of Lippi-Green that indicates that the stereotypes associated with certain accents are perpetuated through the media. They also note that there can be considerable harassment in the workplace related to workers with accents where individuals

\footnotetext{
${ }^{13} \mathrm{An}$ example of this would be a child that grew up as bilingual and maintains certain accented language features when speaking with their parents and those of a previous generation but drops the accent when speaking with anyone else.
} 
may mock the accent. They also note that employers will sometimes tell employees that have an accent that this makes them unacceptable to do a job though they do point out that these foreign accents are not unintelligible. ${ }^{14}$

Agata Gluzek et al.(2011) worked on the "social-psychological orientations of nonnative English speakers in the United States" and how this is affected by their accent. The research group considered the question of the value of a given accent and its ranked value amongst other nonstandard American English accents. The conclusion seemed to intimate that something is wrong with the speech of an individual if it was accented and that this deficiency needed correction for the individual to fit into their new social context. They also broached the issue of interventions and how they might be designed in order to correct this deficiency (Agata Gluzek et al. 32). They did, however, recognise that more than just the accent needed adjusting and that the ingroup also needed to adjust their biases. It also recognised, as did the data of many of the other many other research projects, that an accent does not necessarily affect whether the speaker is understood or not (Agata Gluzek et al. 39) Stigmatisation is not always imposed, but sometimes also self-imposed. The accented speaker may feel as though they do not fully belong in the society in which they are living. This has been noted in numerous studies. ${ }^{15}$

\section{Should an Accent Extinguishing?}

Language teachers often deal with accents as something requiring an intervention. The accent is a mistake that requires correcting. ${ }^{16}$ In order to correct the accent of those individuals who are perceived to speak with a substandard pronunciation, rhythm, or tone, many different approaches are employed. Students are taught to:

- Listen more carefully to how native speakers pronounce words in everyday conversations.

- Pay careful attention to how the tongue and lips form sounds

- Pay attention to where the accent falls in a word

- Use recordings to help with tedious practice exercises

- Record one's own efforts at speaking a language and compare it to native pronunciations

- Some have gone as far as suggesting that oscilloscopes, handheld ultrasound devices, or spectrograms be used by language learners to improve their pronunciation

However, if one were to employ these techniques, the student's language production would become so slow and tedious that it would become discouraging for the student and the listener. Moreover, it would serve to raise the student's affective barriers to the point of the student becoming incapable of saying anything at all, for fear of making a mistake.

It is unnecessary to extinguish the accent for a foreign-accented speaker in order for the foreign-accented speaker to communicate with individuals who speak in a standard pronunciation effectively. Accented language production, even heavily accented language production has been shown not to be an impediment to effective communication of complex ideas. ${ }^{17}$ Perhaps more effort should be put into changing how accents are received by the

\footnotetext{
${ }^{14}$ This view is supported by Huang et al. (2013) in their study of non-native accents and workplace glassceilings.

${ }^{15}$ Trudgill (1992), Lindemann (2005), Szabo (2006), Ng (2007), Gluszek \& Dovidio (2010), Lev-Ari \& Keysar (2010), Gluszek et al. (2011), Derwing \& Waugh (2012).

${ }^{16}$ Munro\& Derwing (1995),Derwing\& Munro (2009), Gluszek et al. (2011), Derwing\& Waugh (2012).

${ }^{17}$ Politzer (1978), Munro\&Derwing (1995), Derwing\&Munro (2009), McGlone\&Breckinridge (2010), Reid et al. (2019).
} 
ingroups that speak in native-accented languages. Or, perhaps, we must simply come to terms with the reality that prejudice against audible minorities will remain an acceptable form of discrimination because it is so widely practised and not considered improper. However, the problem with this form of discrimination is that it is built on myths and fallacies remains.Does the "proper" or high-status accent make onemore intelligent? No, it does not. Does the "proper" or high-status accent make one inherently more trustworthy? It does not do that either. In fact, a high-status accent might be used to deceive the listener. In the end, accent says little about the speaker, but might say volumes about the listener who is using it develop what may be an entirely incorrect image of their interlocutor.

It allows them to fit in. It allows them to be perceived as smarter or more trustworthy, but that has nothing to do with the speaker and has everything to do with the listener's culturally determined prejudices. It may give the impression that they have tried to fit in.

\section{Bibliography}

"Audible Minorities Get Help with Accents." CBC. 27.3.2009.

Bouchard Ryan, Ellen, et al. (1982). Evaluations of Middle-Class and Lower-Class Speakers of Standard American English and German-Accented English. Journal of Language and Social Psychology, 1(1) 51-61.

Bouchard Ryan, Ellen, et al. (1977). Reactions Toward Varying Degrees of Accentedness in the Speech of Spanish-English Bilinguals.Language and Speech, 20(3), 267-273.

Cargile, Aaron C. and Howard Giles (1997). Understanding Language Attitudes: Exploring Listener Affect and Identity.Language \& Communication, vol. 17(3), 195-217.

Cauldwell, Richard (2014). What Does Your Accent Say about You? British Council. Voices Magazine,June.

Council of Europe. Language Policy Division (2009). Relating Language Examinations to the Common European Framework of Reference for Languages: Learning, Teaching, Assessment (CEFR). A Manual.

Derwing, Tracey M, and Murray J Munro (2009). Putting Accent in Its Place: Rethinking Obstacles to Communication.Language Teaching, 42(4), 476-490.

Derwing, Tracey, and Erin Waugh (2012). Language Skills and the Social Integration of Canada's Adult Immigrants. IRPP Study, 31, 1-33.

Dobrow, Julia R., and Calvin L. Gidney (1998). The Good, the Bad, and the Foreign: The Use of Dialect in Children's Animated Television.Annals of The American Academy of Political and Social Science, 557, 105-119.

Fuertes, Jairo N., et al. (2012). A Meta-Analysis of the Effects of Speakers' Accents on Interpersonal Evaluations. European Journal of Social Psychology, 42(1), 120-133.

Gatbonton, Elizabeth, et al. (2005). Learners' Ethnic Group Affiliation and L2 Pronunciation Accuracy: A Sociolinguistic Investigation. TESOL Quarterly: A Journal for Teachers of English to Speakers of Other Languages and of Standard English as a Second Dialect, 39(3), 489-511.

Gluszek, Agata, et al. (2011). Social Psychological Orientations and Accent Strength.Journal of Language and Social Psychology, 30(1), 28-45.

Gluszek, Agata, and John F Dovidio (2010). Speaking with a Nonnative Accent: Perceptions of Bias, Communication Difficulties, and Belonging in the United States.Journal of Language and Social Psychology, 29(2), 224-234.

Hogenboom, Melissa, What Does Your Accent Say? BBC. 9.3.2018.

Huang, L., Frideger, M., \& Pearce, J. L. (2013). Political skill: Explaining the effects of nonnative accent on managerial hiring and entrepreneurial investment decisions. Journal of Applied Psychology, 98(6), 1005-1017.

Jiang, X. et al. (2018). Neural Architecture Underlying Person Perception from in-Group and outGroup Voices.NeuroImage, 181, 582-597.

Kang, Okim and Donald L. Rubin (2009). Reverse Linguistic Stereotyping: Measuring the Effect of 
Listener Expectations on Speech Evaluation.Journal of Language and Social Psychology, 28(4), 441-456.

Kinzler, Katherine D., et al. (2007). Native Language of Social Cognition.Proceedings of the National Academy of Sciences of the United States of America, 104(30), 12577-12580.

Lev-Ari, Shiri and Boaz Keysar (2010). Why Don't We Believe Non-Native Speakers? The Influence of Accent on Credibility.Journal of Experimental Social Psychology, 46(6), 1093-1096.

Lindemann, Stephanie (2005). Who Speaks 'Broken English'? US Undergraduates' Perceptions of Non-Native English 1. International Journal of Applied Linguistics, 15(2), 187-212.

McGill University; Do We Trust People Who Speak with an Accent? (2018).NewsRx Health, 31.

McGlone, Matthew S. and Barbara Breckinridge (2010), Why the Brain Doubts a Foreign Accent. Scientific American. September 21.

Munro, Murray J., and Tracey M. Derwing (1995). Foreign Accent, Comprehensibility, and Intelligibility in the Speech of Second Language Learners.Language Learning, 45(1), 73-97.

Ng, Sik Hung (2007). Language-Based Discrimination: Blatant and Subtle Forms.Journal of Language and Social Psychology, 26(2), 106-122.

Politzer, Robert L. (1978). Errors of English Speakers of German As Perceived and Evaluated by German Natives.Modern Language Journal, 62(5.6), 253-261.

Reid, K., Trofimovich, P., and O’Brien, M. (2019). Social Attitudes and Speech Ratings: Effects of Positive and Negative Bias on Multiage Listeners' Judgments of Second Language Speech.Studies in Second Language Acquisition, 41(2), 419-442.

Szabo, Michelle (2006). 'I Meant to Say That': How Adult Language Learners Construct Positive Identities Through Nonstandard Language Use.TESL Canada Journal, 24(1), 21-39.

Trudgill, Peter (1992). Ausbau Sociolinguistics and the Perception of Language Status in Contemporary Europe.International Journal of Applied Linguistics, 2(2), 167-177.

Wang, Ze, Aaron D. Arndt, Surendra N. Singh, Monica Biernat, and Fan Liu (2013). 'You Lost Me at Hello': How and when accent-based biases are expressed and suppressed.International Journal of Research in Marketing,30(2), 185-196. 